\title{
Comparative advantages and the exploitation of environmental resources
}

\section{Diego Azqueta}

Lecturer in Economic Theory,

University of Alcalá

\section{Daniel Sotelsek}

Professor of Economic Theory,

University of Alcalá
This article analyses five types of international trade based on the competitive advantages afforded to under-developed countries by their environmental resources endowment. First of all, specialization of such countries in the production of highly polluting goods and services is studied, recalling the conventional specialization in the production and export of goods making intensive use of natural resources. The commercial exploitation of the recreational services of natural parks and the exploitation of biodiversity in pharmaceutical research is then referred to. The use for profit of some environmental services involving these resources which are in the nature of public goods and which would require some type of bilateral or multilateral international agreement is addressed. The access of these countries on an equal footing to a number of global and common resources is then considered, and finally some conclusions are presented. According to these conclusions, it is hard for trade relations between developing and developed countries, based on specialization in the use of the endowment of environmental and natural resources, to provide any solution to the problems of poverty and environmental degradation. However, more efficient, more imaginative and, in the final analysis, more equitable exploitation of these resources could make a much bigger contribution to the solution of these two serious problems. In this case, in order to attain economic and social efficiency it is necessary to receive the collaboration of the advanced countries, in view of the fact that environmental resources are in the nature of public goods. 


\section{I}

\section{Introduction}

Two of the most serious problems facing mankind at the close of the twentieth century are more and more closely intertwined in an increasingly integrated economy: the problem of poverty, and that of environmental deterioration. Although the relation between the two has been abundantly documented (Goodstein, 1995, chap. 19), it would unfortunately appear that the growth processes of the underdeveloped economies, in so far as they take place, do not guarantee their solution. Indeed, the empirical data show that the environmental indicators display a U-shaped form of evolution: the problems tend to get worse with the growth process until they reach a turning point, at their lowest level, after which the quality of the environment begins to improve. This turning point takes place at different levels of per capita income, depending on the indicator under analysis: in general, it takes place when the countries reach a per capita income level similar to that of Mexico (Grossman and Krueger, 1995). However, this improvement is limited to local environmental problems: in the case of global-level problems, the growth process does not appear to be accompanied by such possible improvements (Shafik, 1994). This is probably due, on the one hand, to factors connected with the patterns of consumption that accompany the growth process itself and, on the other, to the fact that this growth takes place in the context of an increasingly integrated economy in which international trade flows may be facilitating this transfer of pollution from the more highly developed economies to the poorer ones. This is shown, at least from a theoretical point of view, by studies which have incor-

$\square$ Preliminary versions of this study were presented at the Department of Economics of the Universidad de la República (Montevideo, Uruguay), the University of Corrientes (Argentina), the Second International Economics Symposium held at the Instituto Tecnológico de Monterrey (Mexico), and the Institute for the Ecodevelopment of the Amazonian Region of Ecuador (Quito), benefiting greatly from the ensuing discussions. The authors wish to express their gratitude for the comments made by J. M Naredo (Fundación Argentaria, Madrid), P. Biffani (Geneva) and two anonymous referees. This study also received research assistance from the Subdirección General de Formación y Promoción del Conocimiento of the Ministry of Education and Culture of Spain. porated environmental variables in international trade models (Copeland and Taylor, 1995a).

This article aims to show that the present trade relations between underdeveloped and developed countries, which are the result of specialization based on the countries' environmental and natural resource endowments, are hardly likely to provide a solution to the problems of poverty and environmental degradation. In contrast, a more efficient, more imaginative and, in the final analysis, more even-handed form of exploitation of those resources could do a great deal more to solve them. In this case, in order to achieve greater economic and social efficiency the collaboration of the advanced countries would be required, because these resources are in the nature of public goods, but this would ultimately redound to the benefit of all concerned.

We will therefore analyse five different types of international trade based on the comparative advantages given to the underdeveloped countries by their environmental resource endowments. In section II we will deal with the most obvious and questionable of these: specialization by these countries in the production of highly polluting goods and services, that is to say, ecological dumping. In section III we will review the conventional specialization in the production and export of goods that make intensive use of natural resources, both renewable and non-renewable. In both cases, the conclusions reached are not very optimistic with regard to the ability of this type of trade to solve the problems of poverty and environmental degradation, viewed from a global standpoint. In section IV we will bring in a possibility which is assuming growing importance, especially for certain countries: exploitation of the financial gains that can be obtained from certain services related with natural resources and the environment, above all the recreational services of nature parks and the exploitation of biodiversity in pharmaceutical research. In section $\mathrm{V}$, going beyond the limits of private goods $^{1}$-limits

\footnotetext{
${ }^{1}$ For which it is possible to make a charge, since in principle it is possible to exclude those who do not pay from the possibility of enjoying them.
} 
which are already very blurred in the second of the cases dealt with in the previous section- we will address a much more promising matter: the possibility of deriving profit from some environmental services related to resources which are in the nature of public goods but which, in order to allow them to generate financial flows, require some kind of bilateral or multilateral international agreements.
In section VI, within the same context of public goods and the need for international agreements, we will deal with what is probably the most promising of the environmental assets possessed by the less-privileged countries: their access on an equal footing to a variety of global common resources. Finally, in section VII we will draw some conclusions from all the foregoing.

\section{II}

\section{Ecological dumping}

Ecological dumping occurs when a particular country allows its industries to sell their products at a price which does not include all the marginal costs involved (in this case, by leaving out certain environmental costs), thanks to its more permissive legislation in this respect. Unlike conventional dumping, this form of dumping requires government intervention, but the result is the same: the enterprise in question offers its products at less than cost by, in this case, avoiding a Pigou tax that would have made the private cost equal to the marginal social cost (Rauscher, 1994). In the international sphere, the possibility that the more backward regions might specialize in the production of highly polluting goods should come as no surprise: the theoretical models which simulate the international trade behaviour of two representative countries ("North" and "South") culminate in this type of specialization (Copeland and Taylor, 1995b). Although the rationality of this type of trade policy cannot always be taken for granted in different circumstances -Rauscher (1994) shows that the relaxation of environmental regulations is not always the most suitable policy for promoting exports- there can be no doubt that this is a possibility entertained by a number of countries and is the subject of heated controversy. ${ }^{2}$

\footnotetext{
2 Thus, while some underdeveloped countries consider the concern of the developed countries for the environment in this context as a move to protect their own inefficient production structures and do not hesitate to refer openly to the existence of a new phenomenon, "eco-colonialism" (Rotillon and Tazdait, 1996), the same term is used to denounce the exploitation of the natural resources of underdeveloped countries by the great transnational corporations (Ross, 1996).
}

The variable that explains this pattern of specialization is none other than the difference in levels of per capita income and, hence, in the respective levels of pollution-related supply and demand. However, it is worth going into greater detail on this point, which is sometimes euphemistically presented as merely the result of a difference in the tastes of the respective societies.

Basically, the origin of pollution does indeed lie in the process of production, distribution and consumption of goods and services. As society does not appear to be willing to dispense entirely with the fruits of progress in order to secure an unblemished environment, the problem of determining the "optimum" degree of pollution arises: that is to say, the point at which the benefits of production (the goods and services it provides) are exactly equal to its costs, including those related to environmental deterioration. This is illustrated in figure 1 , where the

FIGURE 1

The optimum level of pollution

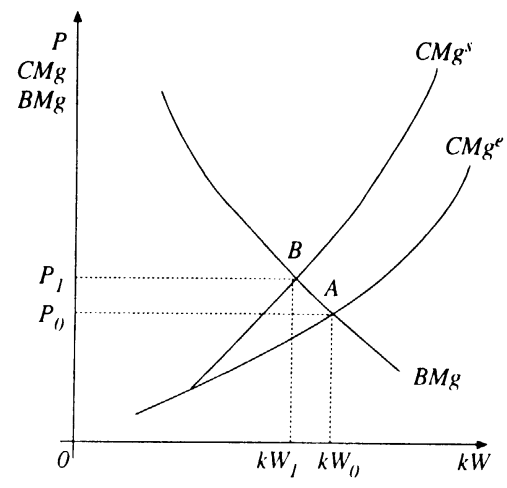

Source: Prepared by the authors. 
vertical axis measures, in pesos, the costs of producing, say, electric power, and the benefits provided by its consumption, while the horizontal axis measures the total amount of electric power produced. Let us assume that the producer companies have a growing cost structure, so that the curve of their marginal costs (the cost of producing the last $k W: C M g^{e}$ ) has the form shown in the figure. The marginal benefits derived by society from the consumption of electric power (the benefits provided by the last $k W$ consumed: $B M g$ ), however, are on a decreasing scale, as shown in the figures, so that the needs covered by them are less and less pressing. If this were all that were involved, society should be at point $A$, since dispensing with the production of one $k W$ (a point slightly to the left of $k W_{0}$ ) would mean that the cost saved would be less than the benefit forgone, while the opposite would be the case if one additional $k W$ were produced.

However, this is not the end of the story: the cost curve analysed so far does not reflect all the costs incurred by society in the production (and distribution) of electric power, but only those that affect the electricity company: it does not include the environmental costs, for example. In conceptual terms, there is no difficulty in introducing them into the calculation. Their effect is all too well known: they are added to the existing costs and shift the marginal cost curve upward $\left(C M g^{s}\right)$. The change caused by this is easy to interpret: the new optimum point is $B$, marked by lower production and consumption of electricity $\left(k W_{l}<k W_{0}\right)$, and hence less pollution, and a higher price to the end-user $\left(P_{1}>P_{0}\right)$. Obviously, the magnitude of the impact will depend on the distance between the old and new marginal cost curves (which are not necessarily parallel: indeed, they will probably diverge to an increasing extent, since pollution has growing costs). In other words, the divergence will depend on the value of the environmental costs imposed on society by pollution. It is not easy to measure this loss of well-being, even though there are a number of more or less suitable methods for doing so (Azqueta, 1994). The European Union, for example, has completed the first stage of an ambitious research project (Project ExternE) whose object is precisely to express in monetary terms the costs generated by environmental pollution in the various cycles of electric power production (European Community, 1995). ${ }^{3}$

Independently of the difficulties of calculation, however, one thing is clear from these studies: the value of the loss of well-being caused by pollution is seen to be greater in proportion to the level of income of the population affected. This is particularly evident, for example, when it is a question of the impact of pollution on the life and health of the population and there is an increase in the rates of morbidity and mortality of the community affected: generally speaking, the lower the income of the persons in question, the lower the value of a "statistical life". This is precisely the argument used to justify ecological dumping: as more backward countries or regions have a lower level of income, the cost of the loss of environmental quality in them is also lower (the marginal cost curve shifts upward by a smaller amount), and hence the production of highly contaminating goods in them will be cheaper. Ultimately, the idea is that deterioration of the environment will cause less loss of well-being in poor countries or regions than in rich ones, thus giving them a comparative advantage. If this were so, the production and export of highly polluting goods and services would be justified, in principle, provided that the pollution were strictly local (otherwise it would generate negative externalities against those who do not themselves benefit from the process), limited in time, and non-cumulative, since otherwise it would be operating against future generations. ${ }^{4}$

\footnotetext{
${ }^{3}$ This process of placing values on environmental assets (or the loss of them) means reducing them to the category of goods. There is nothing intrinsically wrong with goods: it is just that many people feel that the relationship that a person establishes with them (reflected in the fact that he would be willing to exchange them for an amount of money which would keep his level of well-being unchanged) is not what they would consider appropriate for representing mankind's relationship with nature (Anderson, 1993, chap. 9). In other words, the conventional form of valuation is based on the idea of the values used in trade and fails to take account, among other things, of the priceless values that could be modelled through a lexicographic but not a monetary order (Lockwood, 1997). We will return to this point at the end of this study.

${ }^{4}$ The argument that future generations could be compensated through the investment on their behalf of an appropriate part of the benefits generated in the process, replacing natural capital with produced capital, is not really valid; such replacement is not always possible, and moreover no-one has asked them -or could ask them- if they are in agreement with this approach. Indeed, there would be no point in doing so, since they are the ones who are going to be replaced: if there is pollution, the group of persons who will form part of the future generation will be different from that which would have made up that generation if pollution had not taken place. This is a "problem of indetermination" (Elliot, 1995, p. 3), which conventional economic analysis circumvents through the fact that, in its underlying utilitarian philosophy, what matters is the total amount of pleasure and pain, not the particular individuals who experience those feelings.
} 
Obviously, however, this argument raises too many problems to be accepted without reservations:

i) The fact that pollution would appear to be "less costly" among the under-privileged strata of the population is explained by the fact that what most of the methods used to determine the value of the harm caused do is merely to try to find out if people are willing to pay to avoid it. However, it is very well known that the amount that one is willing to pay for something depends, among other things, on what one is able to pay (the demand for a good depends on people's income), and as those who have nothing cannot pay anything, environmental degradation appears to be less costly. The problem is therefore analogous to that of child labour in the underdeveloped countries: without seeking to defend attitudes which involve a good deal of hypocrisy, there can be no doubt that basing a growth process on elements like this can only be considered as evidence of our utter failure as a society. Sacrificing both the physical and mental health of the less-privileged strata of the population cannot be the solution to the poverty problem. The "comparative advantage" of the underdeveloped regions in terms of acceptance of pollution is thus based on an ethically indefensible assumption. The same could be said, of course, of those cases where this type of specialization is explained not so much by the difference in the respective social "demands" regarding levels of pollution (we are assuming here that, in contrast with the previously mentioned case, these demands are identical), but instead by the fact that in underdeveloped countries the government does not reflect these preferences in its actions, whereas in the developed countries it does (Chichilnisky, 1994): this too represents an ethically unacceptable starting point, although at least with regard to the first part of the argument it is probably quite realistic.

ii) The approach taken in order to justify this apparently lower cost of environmental degradation in backward countries suffers from the error of not taking into account a whole series of external effects of such degradation which are not picked up in the valuation methods but nevertheless help to determine the cost of the damage done: people may be obliged to accept substandard environmental conditions because they need a job, but this will affect not only their own health (and that of their neighbours), with consequent costs in terms of public health and/or the corresponding loss of human capital, but also the durability of urban infrastructure, the cost of maintaining and cleaning movable and immovable assets, the productivity of nearby agricultural and forestry operations, etc. (Azqueta, 1994, chap. 10). It is highly unlikely that the affected person will take account of all these indirect effects of pollution when evaluating the costs it entails for him: it would be necessary to apply a series of well-calibrated indirect valuation methods which take all of these externalities into account. Thus, when the cost of such specialization for the country as a whole -and not just for those directly affected- is analysed, these apparent "comparative advantages" could turn out to be substantially reduced.

iii) Finally, acting in this way means reducing the health of human beings to the level of a mere good: a good consumed on an individual and exclusive basis, as a function of purchasing power, and exchangeable for a given sum of money -a good whose production and consumption are, in the final analysis, left in the hands of the market (Anderson, 1993). It is unlikely, from an ethical standpoint, that the social consideration of health as a mere item of merchandise would be acceptable; most likely society would prefer, at least ideally, a different kind of solution.

To sum up, then, ecological dumping is no more justifiable than child labour. It is not an ethically acceptable solution for the problem of poverty, and it goes without saying that it does not seem likely to solve environmental problems. 


\section{III}

\section{The exploitation of natural resources}

In this section we group together everything that is usually considered as renewable or non-renewable natural resources in the literature: all attributes of the earth, whether living or inanimate, that mankind exploits as a source of food, raw materials or energy. ${ }^{5}$

Depressed areas which are fortunate enough to possess some kind of natural resource can achieve comparative (and even absolute) advantages in the production of goods and services that make intensive use of that resource. This is something which is so obvious that it is not worth dwelling further on it, except perhaps to recall some equally obvious aspects regarding the limits imposed by considerations of efficiency and equity on the exploitation of these resources. To this end, we will divide the analysis into two main parts:

\section{Renewable resources}

Renewable resources pose a problem which is simple only in appearance. Two of the most typical cases are probably fisheries and forests, and we will therefore refer to these two examples. Their analysis will, in addition, provide an opportunity to perceive some of the problems involved in institutional arrangements regulating their exploitation.

Under the market system, the management of a fishery will seek to maximize the present value of the net monetary flows generated by its commercial exploitation, from a purely financial perspective; that is to say, by marketing the biomass caught, which is what a market values. Let us assume that the growth rate of this biomass $(x=d x / d t)$ is a positive function of its intrinsic growth rate $[H(x)]$ and the rate of extraction $(y)$, which is itself a function of the cost of fishing $(C)$ and the expected price for the fish caught $(P)$ :

\footnotetext{
${ }^{5}$ Although Reed (1994) cites this definition, he is not completely in agreement with it, as it does not include "gifts" such as clean air and unspoilt nature. It is a very suitable definition for our purpose here, however, as these "gifts" will in fact be analysed in subsequent sections.
}

$$
\dot{x}=H(x)-y
$$

Figure 2 shows this situation.

On the basis of this behaviour equation, if there is free access to the resource, the economic agents (the fishery companies) will try to solve a problem of conditioned maximization in which the control variable is the fishing effort $(y)$, whose optimum value is given as a function of the cost of extracting the biomass $(C)$ and the expected price for the latter $(P)$. When this ratio is not very high $\left[(P / C)_{0}\right]$, the resource could be managed in a sustainable manner, since the optimum level of extraction is potentially compatible with positive growth rates of the stock of fish. When this not so, however $\left[(P / C)_{1}\right]$, the attempt to secure maximum financial benefits will prevent this equilibrium from being attained and the resource will tend to be depleted, since the high rates of extraction will prevent its natural regeneration.

Let us now look at the case of a forest managed under some form of private or common ownership which, as it prevents free access to it, permits the planning of its rate of exploitation as a renewable source of timber with an eye to the future. The problem of conditioned maximization clearly arises here in an inter-temporal context in which the objective variable is the net present value of the yields that the exploitation of the resource will generate in the

FIGURE 2

Optimum exploitation of a freely accessible renewable resource

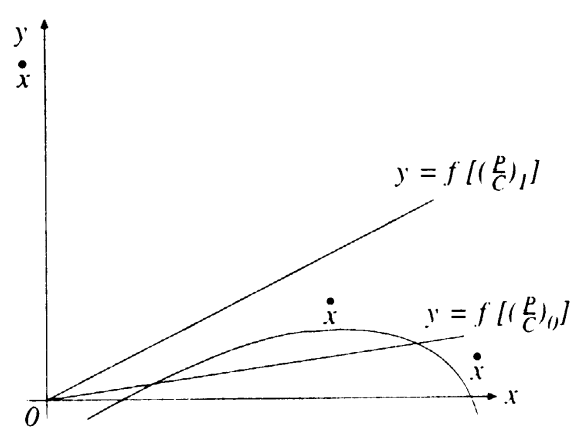

Source: Swanson, 1994. 
course of its useful life. Maintaining the previous behaviour equations and adapting the nomenclature to the present case, the problem posed is:

$$
\max \int_{0}^{t}[P(y) y-C(x) y] e^{-r t} d t
$$

subject to:

$$
\dot{x}=H(x)-y
$$

where $P$ is the expected price of the timber, $C$ its cost of extraction and $r$ the yield on capital in the financial system.

The appearance of an opportunity cost for the capital invested $(r)$, which acts as a discount rate for updating the value of the flows over time, may have the undesirable consequence that sustainable management of the resource may be unprofitable if its natural growth is relatively slow, as shown in figure 3 (Swanson, 1994). Indeed, in this second case the internal rate of yield offered by sustainable exploitation of the asset is systematically below the opportunity cost of the capital involved. Unlike the previous case, it is not free access that prevents maintenance of the resource, but the fact that the yield on the natural capital (measured by the biological growth rate of the wood, and assuming that the price of the latter is constant) cannot compete with the alternatives offered by the financial system. ${ }^{6}$

In many cases the macroeconomic circumstances of the underdeveloped countries themselves aggravate these problems. Thus, the shortage of foreign exchange due to the structural imbalance in the balance of payments (reflected in a very high implicit cost of foreign exchange) leads the public sector to adopt a number of measures which encourage the commercial exploitation of natural resources for export, because in the short term this helps to solve the problem, even though it is not the most profitable option from the economic point of view (because of

\footnotetext{
${ }^{6}$ The results that can be reached in the two cases analysed show the importance of the institutional aspects affecting exploitation; insecure land tenure, for example, reduces the value of the upper limit of the integral ( $t$ ) in equation (2), by reducing the relevant time horizon for the decision-maker and making investments which bear fruit in the medium and long term (forestry) less profitable than those which produce greater yields in the short term (conversion of land for crop-growing or stock-raising), even though overall the latter option gives lower yields (Gottfried, Brockett and Davis, 1994).
}

FIGURE 3

Optimum rate of exploitation over time of a privately owned renewable resource

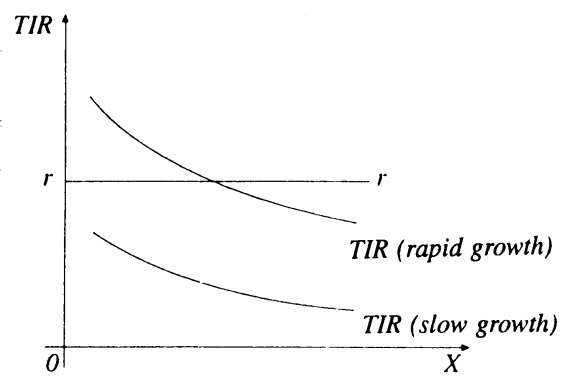

Source: Wanson, 1994.

the negative externalities it generates and its opportunity cost), while in the medium term it is harmful to the environment and ecologically unsustainable (Azqueta, 1992). ${ }^{7}$ It is therefore worth making a brief analysis of the controversy which has arisen over the adoption by a number of underdeveloped countries of measures restricting trade in certain natural products (Lee, 1996).

The fact that some developing countries have prohibited the export of wood in the rough, for example, has been questioned by the importing countries on the grounds that the use of such wood leads to greater environmental efficiency (Anderson, 1996). The developed countries, with their better technology and more highly skilled labour, are indeed more efficient in the use of wood as a raw material in the production process, so that the export of wood in the rough makes it possible to reduce the amount of wood used per unit of final product. Furthermore, the likely reduction in the local price of wood due to the export prohibition may increase its consumption and

\footnotetext{
${ }^{7}$ In the case of Costa Rica, for example, the increase in the demand for beef in the developed countries led to an increase of $3.5 \%$ per year in the area devoted to pastures between 1965 and 1990, often with support from foreign finance and development assistance programmes. This resulted in a progressive loss of tropical forest, whose area went down by $2.8 \%$ per year over the same period, with consequent deforestation, and the loss of $50 \%$ of the area devoted to (ecologically sustainable) traditional agriculture, with a corresponding fall in employment and production and an increase in the nutritional deficiencies of the local population (Pearce and Warford, 1993).
} 
make it less efficient, unless it is offset by a suitable policy of licences for cutting down trees. However, this latter view is based on very short-term arguments (almost an analysis of comparative static efficiency) and does not take account of the dynamic effects on development of a policy which makes it possible to retain within the country the operations that generate most added value (Goodland and Daly, 1996). ${ }^{8}$ In the medium and long term, the environmental benefits of the process of generation of income and employment that such a prohibition implies are probably greater than the effects of the loss of efficiency in the short term. An export prohibition of this type must be accompanied, however, by some type of economic alternative. Outright prohibition of marketing wood, far from preserving this resource, generally militates against this when the occupation of territory has already taken place or is under way: the profitability of forestry operations goes down compared with agriculture or stock-raising in the same areas, due to the reduction of the value $\mathrm{P}$ in equation (2), thus encouraging the clearing of forests to permit cultivation of crops or stock-raising. Consequently, before adopting this kind of measures it is necessary to make a careful institutional analysis of the situation. In this respect, certificates of origin of wood which guarantee the sustainability of the forestry operations from which the wood comes ${ }^{9}$ could be a better alternative than outright prohibition. At all events, this possibility should be viewed in its true perspective: as noted by Gottfried, Brockett and Davis (1994), sustainable forest management (which at least saves the secondary forest, if not the primary one) requires a large area of land per family in order to ensure an acceptable income, and this sheds serious doubt on the possibility of giving the whole population of the area a satisfactory standard of living by this means.

In any case, it should be borne in mind that the commercial exploitation of various natural resources

\footnotetext{
${ }^{8}$ Indonesia, which was one of the largest exporters of wood in the rough during the 1970s (it exported as much as $40 \%$ of the world total), introduced such a prohibition in 1985, invoking Article XX of the General Agreement on Tariffs and Trade (GATT). By the mid-1980s, such exports had practically disappeared, whereas exports of wood products amounted to US\$ 3.8 billion in 1991 (Goodland and Daly, 1996). A more negative view of the environmental effects of this substitution is given in Anderson (1996).

${ }^{9}$ Along the lines of the Forest Stewardship Council based in Oaxaca (Mexico).
}

on the basis of their market value, even if sustainable, does not take account of the environmental externalities generated by the resource in question, and these externalities, which may have a much higher economic value, are usually incompatible with this type of exploitation. Taking account only of the values provided by the market is therefore no guarantee whatever that the exploitation of the resource will be socially optimal.

\section{Non-renewable resources}

Non-renewable resources, by definition, cannot be exploited in a sustainable manner. The objective pursued in this case is to share them properly among all concerned: a problem of inter-generational equity. The usual procedure for this purpose is to use what is called "Hotelling's rule", which relates the rate of exploitation of the resource with its price and interest rates (Gómez, 1994). This may not be a very useful rule for solving the problem in practice, but it is useful for expressing it more clearly, since it brings out the fact that non-renewable resources have an opportunity cost which must be added to the cost of their extraction when deciding the rate at which they are to be exploited. This opportunity cost must be calculated and taken into account in order to accurately determine the net benefits from their exploitation, although the conventional national accounts do not do so and therefore provide false figures on the profitability of such exploitation and the resulting growth rates of national income. In this respect, it is worth mentioning the practice which is becoming accepted in the World Bank, which consists of calculating the cost of the investments needed in order to replace, in an alternative project or programme, the services that the non-renewable resources exploited would have provided (Von Amsberg, 1993). ${ }^{10}$

It is also necessary to take account of the environmental impact of the exploitation processes themselves. The study by the European Community (1995) on the

\footnotetext{
${ }^{10}$ It is interesting to note that the prices of non-renewable resources, which should display an upward trend over time, because of the increase in the rents expected from them on account of their growing scarcity, do not seem to behave in this manner. An interesting explanation which has been put forward for this phenomenon is based on the relation which exists between some of these resources and the global pollution caused by their use (in the case of fossil fuels, for example): the limits placed on the emission of pollutants through their use may cause them to be prohibited before their actual physical disappearance, which would be reflected in this form of evolution of their expected prices (Berck and Roberts, 1996).
} 
environmental costs of electric power generation, referred to earlier in this article, is an excellent example of the path to follow. For example, the extraction of petroleum in certain tropical forest areas has an environmental impact which is not limited to that of the operations of the oil company proper, although that impact is by no means insignificant, but goes far beyond it because of the accompanying establishment of human settlements in those areas, which proves to be a much greater threat to the sustainability of the primary forests. This phenomenon suggests that we should not only calculate this impact, as one of the prices to be paid for the extraction of crude oil, but also try to avoid it altogether. In order to do this it would be necessary to take action on the ultimate causes of this phenomenon by seeking to improve living and working conditions in the areas of origin of the potential emigrants in order to try to check this flow of settlers. The lessons learned in the sphere of development economics from Todaro's migration functions and from analysis of the informal sector, which indicate that the creation of jobs in the urban formal sector probably makes unemployment problems worse rather than solving them, could also be perfectly applicable in this case: certain social and infrastructural investments in the area of operations could actually make the situation worse, by raising the expectations of potential immigrants. $^{11}$

Ultimately, what is involved is the solution of a problem which could be summed up, in a highly simplified form, as the need to calculate the social interest rate to discount from the net flow of benefits from the exploitation of non-renewable resources, which it is sought to maximize. The problem is by no means easy, of course: in the final analysis it is a question of inter-generational equity in conditions of uncertainty and irreversibility. ${ }^{12}$

\section{IV}

\section{The exploitation of some environmental services}

Some environmental services of the biosphere have the properties of public goods (non-exclusion and non-rivality in their consumption), possibly modified by the presence of congestion. Administrative measures, however, can impose exclusiveness in their enjoyment and thus allow the appearance of a price for them. This is so in the case of the recreational services of a particular environment (a nature park, for example) for which an admission charge is made; the research possibilities opened up by the biodiversity that exists in a particular nature reserve; or the renting-out of a specific area as a dumping

\footnotetext{
${ }^{11}$ In the case of Ecuadorian Amazonia, the funds that ECORAE receives from the oil companies, which are to be invested in order to secure the sustainable development of the area, would probably achieve this objective more effectively if they were invested in the Loja area (many hundreds of kilometres away) rather than in Amazonia itself. By doing so, an attempt could be made to stop the already very substantial flow of migrants (indeed, one of the main towns of the area where the oil companies are operating, Lago Agrio, is already known as Nueva Loja), which the improvement of living and working conditions in Amazonia would merely serve to foment still further.

${ }^{12}$ See, for example, Sterner (1994) and Weitzman (1994).
}

ground for wastes (even including toxic and hazardous wastes) that the developed world does not want. In view of the similarities that exist between this latter case and the factors we mentioned when dealing with ecological dumping, which would also be applicable here, the following analysis will be limited to the first two cases mentioned above. ${ }^{13}$

\footnotetext{
13 Defending the export of waste to underdeveloped countries with arguments like those mentioned in the section on ecological dumping can have highly negative consequences: Krugman and Obstfeld (1995, p. 91) describe how the collision between apparent economic common sense and morality became unpleasantly obvious in 1992 for Lawrence Summers, chief economist of the World Bank. A World Bank internal memorandum signed by Summers supported the idea that it could be reasonable, in economic terms, for the developing countries to apply rather more permissive environmental standards than the rich countries, since this could give them a de facto comparative advantage in some polluting industries. The text of the memorandum was filtered to the press, giving rise to a flood of bad publicity (People magazine included Summers on its list of the worst enemies of the environment), and in December of that year it appeared that the controversy over that memorandum was responsible for blocking the expected appointment of Summers as chief economic adviser to President Bill Clinton.
} 


\section{Exploitation of nature parks for recreational purposes}

Nature parks are becoming more and more important as the centre of attraction for a particular type of tourism which seeks precisely the sort of experiences offered by nature in the wild. The presence of such nature-lovers in the environment they want to visit has a by no means negligible multiplier effect on the economy of the area (transport services, accommodation, etc.). In Costa Rica, for example, in 1991 the nature parks attracted half a million visitors who generated over US\$ 330 million of foreign exchange, thus becoming the country's second largest industry (Grey, 1995, p. 5). Unlike other natural assets sought by tourists for leisure purposes, these parks are valued for their unspoilt character, and demand studies tend to show that visitors are very sensitive to everything - such as overcrowding or excessive commercialization- that affects their enjoyment of nature (Dixon, Scura and Van't Hof, 1995; Shah, 1995).

Economic analysis reveals that these assets have at least three sources of direct value:

i) A financial value for the owners of neighbouring properties, which can serve as a base for tourism operations and therefore gain in value. Other owners, however, may be adversely affected if the protection of the environment means that they cannot continue to carry out a number of economically profitable activities (farming, hunting, stock-raising, etc.).

ii) An economic value for society as a whole, due to the multiplier effect that these operations have on income and employment in the area (assuming that this is not a zero-sum game) or in the country as a whole. Ultimately, the public budget is also favoured through the higher income generated by the increase in economic activity, though in this case the impact is purely redistributive.

iii) The recreational value proper arising from the well-being experienced by visitors, which is reflected in the value of the net consumer surplus, as determined by, for example, the journey cost or contingent valuation methods (Azqueta and Pérez, 1996).

The problem facing the managers of these areas, when seeking to maximize their social value, is therefore to find the difficult balance between public and private financial profitability (in the medium and long term), the multiplier effect on employment and income in the economy, and the preservation of the essential ecological functions of the environment (maintaining biodiversity, for example). All this must also be achieved without losing sight of the interests of the local population, who are usually adversely affected by the protection of the area (since restrictions are imposed on activities in it and access to resources traditionally used in the past) yet do not benefit from the multiplier effect, since normally these effects are felt mostly in the urban centres where tourists stay. In this respect, if the presence of a substantial consumer surplus among the visitors is confirmed, attempts could be made to turn this value (a positive disposition to pay for enjoyment of the recreational services of the environment) into a flow of financial resources (through entry charges, for example) that could be directed in favour of those sections of the local population who have been adversely affected.

Unfortunately, certain well-meant conservation policies may prove to be clearly harmful both to the interests of the inhabitants of the surrounding area and to the objective of conservation itself. This may be so, for example, as a result of the inclusion of certain species in Appendix I of the Convention on International Trade in Endangered Species (CITES), which prohibits all trading of the corresponding products. The results of such a measure must be very carefully analysed, for when a species thus protected competes with others which are not, the final result may be counterproductive, since the measure reduces the financial value of the endangered species compared with its competitors, thus reducing its practical value for the local population in an attempt to save it at the global level. Thus, if two species (say, elephants and cattle) compete for territory, the local population is being encouraged to displace elephants, which have no practical value, to make room for cattle, which do have such value. We already saw that the same thing can happen with the prohibition of exports of certain types of wood. If the non-protected species is a natural predator of the protected species, the fact that the prohibition eliminates the financial value of the latter makes its protection less 
profitable, and this state of affairs becomes even more unfavourable if the predator does have a financial value (Swanson, 1993; Schulz, 1996). ${ }^{14}$

The foregoing can be expressed in formal terms on the basis of figure 4 (similar to figure 2 ). The growth function of the resource $H(x)$ depends on a series of variables which are not shown in figure 4 because of the implicit introduction of a caeteris paribus clause but which obviously influence the evolution of the resource not only in terms of the land devoted to its development (with its corresponding load capacity) but also in terms of the execution of a number of collateral investments (Swanson, 1994). These measures, like the expansion of the area devoted to the resource, shift the curve outward, permitting higher growth rates of the resource. In contrast, when the resource loses its economic use value these variables move in the opposite direction, causing the growth curve to contract and making ecologically sustainable management more difficult.

\section{Pharmaceutical research and biodiversity}

The case of biodiversity and the pharmaceutical industry is more complex. Some underdeveloped countries possess an asset in this respect from which they can try to earn money by offering to allow the pharmaceutical industry to exploit it in return for payment. In this way, they could not only preserve the environment but also finance the development process. However, it is necessary to get a clear picture of the possibilities in this field before beginning to celebrate. Firstly, serious estimates of the payments that the countries owning such biodiversity might be

\footnotetext{
${ }^{14}$ Barnes (1996) has made an interesting study on the possible effects in Botswana of the inclusion of elephants on the protected list. Taking into account both the opportunity cost of the land occupied by the elephants and the costs of protection which have an impact on management costs (keeping watch, control, etc.), he puts forward what he considers would be the best strategy for managing this resource. Using the framework of social project evaluation for this purpose, and introducing the corresponding implicit prices, he comes to the conclusion that the controlled reintroduction of a number of prohibited practices (hunting for sport, hunting by the local population, use of elephant meat in crocodile farms for the marketing of skins, etc.) would markedly improve the economic value (for the country) and the financial value (for the local population) of elephants and hence would ultimately make a greater contribution to their preservation. The prohibition of trading elephant-based products was needlessly reducing their economic use value solely to that deriving from their mere observation.
}

FIGURE 4

Growth rate of a renewable resource

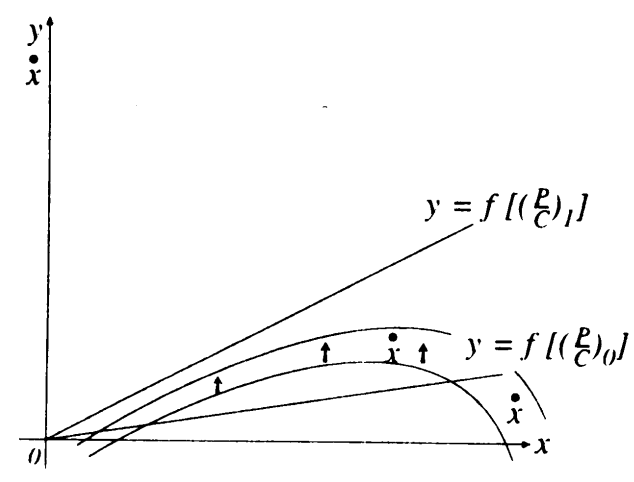

Source: Adapted from Swanson, 1994.

offered for its use (bearing in mind that they are calculated as a percentage of the profits that the pharmaceutical company makes from the commercial exploitation of the product finally obtained) give really modest sums which would hardly be sufficient to cover the preservation of this asset (Simpson, Sedjo and Reid, 1996). Secondly, it should be noted that in order to carry out this operation it is necessary first of all to invest in the conservation of the biodiversity of a particular environment, and as it is a public good this can only be done by the administration. The authorities of such countries generally provide a number of extra services (identification and classification in local laboratories and research centres) for which they make no charge, and if we add to this the opportunity cost of the land set aside for the preservation of biodiversity we see that the "big deal" may prove to be financially ruinous. Barbier and Aylward (1996) calculated that the net present value of the benefits that Costa Rica would receive in this respect from the preservation of a particular natural space for a period of 40 years would amount to US\$ 4.6 million, whereas the net present value of the costs involved (including the opportunity cost of the protected land) would come to US\$ 240 million over the same period.

It is therefore obviously very important to take into account the institutional framework within which these kinds of agreements are signed (although the calculations of the above-mentioned authors do not hold out much hope on this level) and the need for coordination among the different coun- 
tries possessing biodiversity (which can to some extent take each other's place in this respect), so that they will not compete with each other and thus lose a large part of the benefits of exploiting that biodiversity commercially. It is also worth noting that the institutional framework in which these transactions take place does not recognize that the true owners of these areas, the indigenous peoples, have intellectual property rights for a large number of medicines and treatments which they have developed through their knowledge of nature and which have brought the pharmaceutical industry enormous profits (Azqueta-Bernar, 1996).

At all events, subject to the above reservation regarding the pharmaceutical industry, such efforts to derive gain from some natural resource- and environment-linked services undoubtedly seem to have positive aspects. Nevertheless, it is worth mentioning a couple of obvious limitations of this sale of environ- mental services with regard to the objectives of reducing poverty and environmental degradation. Firstly, while there can be no objection to the idea of deriving gains from the recreational services of certain natural areas, this nevertheless leaves out all those natural environments which are not considered as "cathedrals of nature" yet are particularly threatened; it is precisely for this reason that the different forms of protection of natural areas have been evolving in this direction (López Ramón, 1996). Secondly, with regard to the solution of the problem of development, the difficulty is that on the whole these "cathedrals" are not very equitably shared out, and many countries and regions have very few of them. Therefore, while this is probably a better scheme than those analysed earlier, it can nevertheless not be relied on alone to solve the environmental problem of the global preservation of natural areas or the relief of the global problem of poverty.

\section{V}

\section{Internalizing environmental externalities}

A fourth possibility which is undoubtedly interesting and is only beginning to be explored derives from the fact that some natural resources generate a series of positive externalities which can redound to the benefit of all. One of the most obvious cases is the role played by large forested areas in fixing the carbon in the atmosphere. The existence of these positive externalities immediately gives rise to strong tensions between the common interest on the one hand and the private interests of those who consider that they have a right to dispose of the asset and object to the idea of preventing its commercial exploitation and introducing a system which will only bring them benefits very indirectly. ${ }^{15}$ This is a

\footnotetext{
${ }^{15}$ This is precisely why economic analysis is generally against the recognition of private rights over environmental and natural assets which generate various kinds of positive externalities: the smaller the group recognized as owning the resource, the greater the disparity between the financial benefits of its exploitation (which are shared out among a few) and the corresponding environmental costs (which are shared by the whole population).
}

long-standing conflict: the countries which have tropical forests complain that, adducing the general interest, those who did not trouble to preserve their own resources are now trying to prevent them from exploiting them in a financially profitable manner, and moreover the rich countries are not willing to offer many alternative ways of solving the problem of underdevelopment either (for example, by opening up their markets). Let us now look at two undoubtedly significant possibilities in this respect.

\section{Carbon deposits}

From the strictly economic point of view, the foregoing is a typical problem of the generation of positive externalities which do not directly benefit the owner of the resource. One solution could be to try to internalize the benefits provided by these services; in this way, the rest of the world would pay the managers of tropical forests the value of the services rendered by them in retaining a quantity of carbon which, if liberated into the atmosphere, would aggravate the global 
warming problem. This would occur if, for example, they burnt or cut down those spaces to devote them to agriculture and/or stock raising, as indeed many countries which are now developed did in their time.

It is not easy to compute the value of these benefits, but one way which is quite often used is to calculate the economic cost that would be involved in reducing emissions, at their source, by an equivalent amount of carbon through, say, the conversion of industry or the modification of public transport systems. This would enable us to calculate the implicit price of the resource on the basis of this environmental function. Likewise, once the principle that it is necessary to remunerate the environmental functions carried out by certain natural resources is accepted, it would also be logical to remunerate countries which have deposits of fossil fuels (oil, coal) in a similar manner for not extracting them and keeping them instead as carbon deposits (Goodland and Daly, 1996).

\section{Carbon sinks}

The foregoing also points the way to a second possibility which, if treated with the necessary care, could also be interesting. Thus, some developed countries (specifically Canada) are analysing the potential profitability of afforesting or reafforesting land purely for the purpose of absorbing carbon from the atmosphere in order to avoid having to reduce emissions at their source by an equivalent amount to comply with the environmental commitments they have entered into. In this connection, Van Kooten, Binkley and Delcourt (1995) have estimated that the cost to a country like the United States or Canada of fixing one metric ton of carbon by this means would be between US\$ 6.64 and US\$ 10.67: a figure which does not compare unfavourably with the US\$ 1.35 to US\$ 59.41 it would cost to do so by other means, to say nothing of the benefits that the creation of a forest area would bring in other respects. ${ }^{16}$ As well as

\footnotetext{
${ }^{16}$ On the basis of these figures, the authors make an analysis of a possible optimum subsidy policy for both reafforestation and the subsequent use of the wood produced in such a way as to keep the carbon sequestered: $40 \%$ of the wood used for construction still exists after 50 years, while in the case of the wood used for paper manufacture the figure is only 3\% (Sedjo, Wisniewski, Sample and Kinsman, 1995). There would thus be justification for a subsidy for the outright burial of wood, as a way of ensuring minimum return of carbon into the atmosphere.
}

this direct contribution to reducing the amount of carbon in the atmosphere by sequestering it, woods and trees (especially in urban areas) also make an indirect contribution to this aim by reducing the consumption of energy for certain activities. Thus, in countries like those mentioned above, a suitable distribution of trees around dwellings can reduce the demand for air conditioning by as much as $50 \%$ and the need for heating by $15 \%$ (Sedjo, Wisniewski, Sample and Kinsman, 1995). It would also be possible to carry out such operations in developing countries too, by remunerating the reafforestation of marginal land that could even serve as a protective belt for other spaces. The problem is that, because of the economic profitability of this operation, it might seem an attractive proposition to turn mature primary woodlands into a carbon sink, replacing the existing trees with new ones which, managed with this objective, would maximize the amount of carbon sequestered. An option of this type, however, would not stand up very well to cost/benefit analysis, since doing this would cause the loss not only of an existing carbon deposit but also of all the services provided by the rest of the ecological functions of primary forests, whose economic value (according to the data given in the excellent study by Constanza, D'Arge and De Groot (1997)) is very considerable and gives a price per hectare for tropical forests which is a good deal higher than that given by the commercial exploitation of the land as a source of wood, pastureland or any other market option.

In general terms, and for purely illustrative purposes, Fearnside (1997) calculated that the environmental services of the Amazonian rain forest would be worth US\$ 7 billion per year for maintenance of biodiversity, US\$ 24 billion as a carbon deposit, and US\$ 7 billion more for their role in the water cycle. The first two are undoubtedly externalities which benefit the whole of mankind. In the opinion of the author, the first of these should not be subject to reduction with the passage of time, whereas the value of the second should be discounted in this way to reflect the differing value of fixing carbon according to when such fixing takes place. The third (regulation of the water cycle) is of a more local nature, as it covers the role of the Amazonian rain forest as a generator of rain in that general area, together with the impact of that rain on the productivity of agricultural land. At all events, as the author himself acknowledges, these very rough calculations do not include many other 
positive aspects of the Amazonian rain forest, but they nevertheless provide a very good idea both of the magnitudes involved and of the path to follow. ${ }^{17}$ As in the case of exploitation of the recreational services of natural areas, however, one must not lose sight of the fact that although the economic value of the forest, calculated in this way, is probably much higher than that of any other option, in financial terms the change may adversely affect the population which uses the resource and may now be deprived of access to it. Shyamsundar and Kramer (1996), in an interesting analysis in which they combined the production function method with that based on contingent valuation (using for this purpose -in one of the rare examples to be found in the literature- the "compensation demanded" format), calculated the loss of welfare that the inhabitants of the area would suffer through the protection of the Mantadia National Park in Madagascar. The result obtained indicates that the adverse effects would be far from negligible: in this case, their value was almost equal to the commercial value of the rice harvest.

\section{Debt for nature swaps}

The foregoing approach may also be taken to include the debt for nature swaps which were in vogue some years ago between various non-governmental organizations (NGOs) and some developing countries. This system is very simple and well-known: it merely consists of buying public external debt on the secondary market at a heavy discount and changing it with the issuing country for some kind of environmental commitment: creation of new nature reserves,

\footnotetext{
${ }^{17}$ Since some of these environmental benefits are subject both to uncertainty about the future and the irreversibility that would be involved in allowing activities which are financially profitable but incompatible with their maintenance in the long term, this considerably complicates the decision-making process in this respect. Albers, Fisher and Hanemann (1996) studied the case of the Khao Yai National Park in Thailand, modelling the problem of a decision-maker faced with three mutually exclusive alternatives: preservation of the environment, semi-sustainable development of it, and non-sustainable development. Taking account of the possible sequences through a dynamic model and seeking to maximize the net present value in the best of them, the study shows that the conventional open loop strategy of maximizing the target function is inferior to a closed loop strategy of incorporating such uncertainty about the future, which results in better preservation of the environment.
}

expansion and/or improvement of existing ones, etc. ${ }^{18}$ Leaving aside the always thorny questions of sovereignty, the problem with these schemes, apart from their somewhat voluntaristic and unorganized nature, is that they can result in an increase in the price of the debt on the secondary market (because of the increased demand). Such an increase does not benefit the issuing country but instead its creditors (who witness the rise in value of an asset which they feared was virtually worthless), nor does it facilitate subsequent operations of the same kind (as experience seems to have proved). It would therefore be preferable to place payment for such positive environmental externalities on a formal basis both in institutional terms, by setting up some supranational body or agency to be responsible for it (which would reduce the problems of sovereignty) and on the strictly economic level, by determining the flows of payments according to some established criterion.

Returning to the dual issue with which we are concerned, this internalization and consequent endowment with financial value of some environmental externalities would appear to be an ideal complement to what we analysed in the previous section from the point of view of nature conservation and protection, all the more so in view of the magnitude of the environmental services acknowledged to be rendered by these resources to mankind as a whole. Unfortunately, it does not seem that the same can be said of their possible contribution to solving the global problem of poverty: not all poor countries or regions -especially the most under-privileged and needy- have been lucky enough to possess such resources and be able to preserve them. Table 1 shows, for example, 
TABLE 1

Selected countries: Area of enclosed forests ${ }^{\text {a }}$

(Thousands of hectares)

\begin{tabular}{lrr}
\hline Bolivia & 44010 & \\
Brazil & 357480 & \\
Colombia & 46400 & \\
Mexico & 46250 & \\
Venezuela & 31870 & \\
Zaire & 105750 & \\
Indonesia & 113395 & $(100 \%)$ \\
Peru & 69680 & \\
Total, 8 countries & 815335 & \\
World total & 1436492 & \\
\hline
\end{tabular}

Source: Stähler, 1996.

a The figure for India (36,450 thousand hectares) was omitted because it was felt that it distorted the global conclusions of the table.

how the main forest masses are distributed at present: a situation which could well be described as oligopolistic. The problem is that this oligopoly is not only not appropriate for solving the global problem of poverty, as we already said, but may even make it more difficult to solve the environmental problems themselves. Thus, Stähler (1996), using the optimum control theory, shows that when the developed countries are willing to pay more and more to maintain a resource as it becomes increasingly scarce and the countries that possess such a resource are few in number and act strategically, the optimum form of behaviour of the latter may lead to a lower equilibrium level of the total stock of the environmental good in question than if no payment were made for its preservation. In this respect, financing specific conservation projects which involve some degree of control over the resource may be a more suitable alternative than indiscriminate payment for its conservation, although they may be less acceptable from the point of view of sovereignty.

\section{VI}

\section{Access to common global environmental resources: a market for pollution rights}

It might seem a contradiction in terms to emphasize the need for more active defence of the environment while at the same time bringing into the discussion the idea of "pollution rights". In reality, however, it is probably not so.

Thus, as already noted in section II of this article, the optimum degree of pollution is not zero, since this would mean giving up the production and consumption of almost all the goods and services on which organized life is based. It would therefore seem that human beings are willing to make use of the biosphere to some extent to satisfy their own needs. ${ }^{19}$ This naturally means making use of its posi-

\footnotetext{
${ }^{19}$ For a discussion of the fascinating problem of whether this is ethically defensible or not, see the articles included in Elliot (1995).
}

tive functions while respecting its limits. Among the most important of those functions is the capacity of the biosphere to assimilate the wastes generated in the processes of production and consumption; as the principles of ecology rightly remind us, this is a closed system in terms of matter, in which human beings take a number of elements out of the biosphere for their processing, use and enjoyment, on the one hand, and return them in the form of wastes and entropy on the other.

However, the capacity of the biosphere to absorb these wastes is limited. So far, because the biosphere is a freely accessible common resource, each person has got rid of his wastes in the environment (the atmosphere, water or the soil) as he saw fit. The application of this law of unrestricted appropriation has brought the problems we are suffering now and calls for a total reformulation of the situation: a reformulation which would be reflected in the establishment of 
limits on what can be returned to the environment in the form of wastes and rubbish; for example, limits on what can be emitted into the atmosphere without endangering the viability of the system. In this respect, since we are dealing with a scarce resource, we may ask how the right to enjoy this environmental service -by emitting $\mathrm{CO}_{2}$ into the atmosphere, for example- should be shared out. These are the "pollution rights" referred to earlier: the right to use the services of the biosphere as a rubbish dump, within the limits represented by the absorption capacity of the system. ${ }^{20}$

The problem posed, then, is to find a means of sharing out these emission permits which is both fair and efficient.

One alternative which has been the subject of many studies, both from the theoretical standpoint and in terms of the simulation of its results, is that of "buying" the participation of underdeveloped countries in schemes for the reduction of global pollution. Examples of such studies include those by Bohm and Larsen (1994) and Larsen and Shah (1994) on $\mathrm{CO}_{2}$ and the study by Klaasen, Forsund and Amann (1994) on $\mathrm{SO}_{2}$. Let us take a look at one of them in greater detail.

The above-mentioned study by Larsen and Shah (1994), whose main results are summarized in table 2 , is a good illustration in this respect. The authors analyse the possibility of establishing a system of marketable permits for the emission of carbon dioxide $\left(\mathrm{CO}_{2}\right)$, with a view to stabilizing emissions in the year 2000 at the 1987 levels. ${ }^{21}$ The problem is that if an agreement of this nature is to have a chance of being effective, one cannot leave out the underdeveloped countries (the non-OECD countries, to simplify the matter), which are responsible for $43 \%$ of all emissions according to 1987 data. However, the incentives these countries may have for participating in a scheme for the reduction of emissions are rather

\footnotetext{
${ }^{20}$ The problem will not actually be posed in terms of individual pollutants (such as $\mathrm{CO}_{2}$ ) but of desirable objectives and of the contribution of groups of variables to their attainment (Schaltegger and Thomas, 1996). For the analysis we are about to make, however, this distinction is irrelevant.

${ }^{21}$ At the summit meeting on climatic change held in the city of Kyoto the objectives were somewhat different; the main thing, however, is the theoretical framework provided by this study, which would be easily adaptable to changes of this nature, without affecting the basic results.
}

limited. Taking into account the limits presented as an objective and the marginal costs of reducing emissions of $\mathrm{CO}_{2}$ (using the extended function proposed by Nordhaus for this purpose), ${ }^{22}$ Larsen and Shah come to the conclusion that the unit price of an emission permit would be US\$ 58 per ton. On the basis of this, we can construct the cost/benefit function applicable to each country that participated in the scheme, depending on how the permits are awarded and assuming that, in equilibrium, each country will reduce its emissions until the marginal cost of doing so is equal to the price of the permit.

On this basis, various forms of distribution of these "emission permits" are analysed, always bearing in mind that a country will have an incentive to participate in such agreements only if it receives an amount of money, in respect of permits granted, which exceeds the benefits it forgoes through its participation. Let us look at four possible allocation schemes: ${ }^{23}$

i) Allocation of rights as a function of population, so that the per capita amount of permits is equal in all countries ( 0.915 tons), as suggested some years ago by the Indian economists Agarwal and Narain (Martínez-Alier, 1992) and supported by such respected figures as Herman Daly (Goodland and Daly, 1992). From a purely logical standpoint, it would seem reasonable that every human being should have the same right to use the atmosphere (while respecting the limits mentioned earlier), so that every person should have the same right to emit pollutants. This assertion could be modified, if this is considered desirable, to take account of the past and present responsibility of the various societies in creating the problem (the stock of wastes already emitted) and

\footnotetext{
${ }^{22}$ The cost function in question is as follows:

$$
R=1-e^{-0.0054 \mathrm{MC}}
$$

where $R$ is the percentage reduction of emissions of $\mathrm{CO}_{2}$ and $M C$ is the marginal cost of securing this reduction (in dollars per ton).

${ }^{23}$ The article in question also addresses two further questions. The first concerns the problem raised by "free-riders", and it considers that if the allocation is taken into account as just one more variable this will reduce the likelihood that this problem will arise among the OECD member countries, although it acknowledges that this possibility does not disappear altogether. The second concerns the marginal cost function used (which has been hotly debated), and the robustness of the results obtained with various functions is analysed.
} 
TABLE 2

World: Costs (-) and benefits (+) of the different schemes for the allocation of $\mathrm{CO}_{2}$ emission rights

(As a percentage of GDP)

\begin{tabular}{|c|c|c|c|c|c|c|c|}
\hline \multirow{2}{*}{ Country } & \multirow{2}{*}{$\begin{array}{l}\text { Per capita } \\
\text { GDP }^{\text {a }}\end{array}$} & \multirow{2}{*}{$\begin{array}{l}\text { Emissions } \\
\text { per unit of } \\
\text { GDP } \\
(\mathrm{kg} / \mathrm{US} \$)^{\mathrm{a}}\end{array}$} & \multirow{2}{*}{$\begin{array}{l}\text { Per capita } \\
\text { emissions } \\
(\mathrm{kg})^{\mathrm{a}}\end{array}$} & \multicolumn{4}{|c|}{$\begin{array}{l}\text { Allocation options: net advantages as } \\
\text { percentage of GDP }\end{array}$} \\
\hline & & & & $\mathrm{A}$ & B & $\mathrm{C}$ & $\mathrm{D}$ \\
\hline Bangladesh & 166 & 0.18 & 30 & 25.38 & -0.16 & 0.23 & \\
\hline Nigeria & 229 & 0.37 & 84 & 26.63 & -0.93 & 0.35 & \\
\hline China & 286 & 1.87 & 533 & 1.92 & -6.06 & 1.15 & \\
\hline India & 322 & 0.57 & 182 & 7.92 & -1.73 & 0.47 & \\
\hline Pakistan & 325 & 0.39 & 128 & 11.11 & -0.68 & 0.31 & \\
\hline Indonesia & 443 & 0.35 & 153 & 6.41 & -0.14 & 0.23 & \\
\hline Zimbabwe & 598 & 0.77 & 463 & 5.58 & -2.04 & 0.52 & \\
\hline Egypt & 709 & 0.54 & 380 & 1.98 & -1.75 & 0.48 & \\
\hline North Korea & 889 & 2.06 & 1834 & -3.58 & -9.10 & 1.62 & \\
\hline Mexico & 1715 & 0.55 & 943 & -0.10 & -1.46 & 0.43 & \\
\hline Brazil & 2145 & 0.17 & 356 & 0.97 & 0.42 & 0.14 & \\
\hline South Africa & 2493 & 0.92 & 2292 & -2.72 & -3.63 & 0.77 & \\
\hline Venezuela & 2629 & 0.49 & 1276 & -0.39 & -1.30 & 0.41 & \\
\hline South Korea & 3121 & 0.34 & 1067 & -0.64 & -0.13 & 0.22 & \\
\hline Poland & 1700 & 1.96 & 3338 & -5.83 & -7.39 & 1.36 & \\
\hline Yugoslavia & 2700 & 0.52 & 1403 & -0.42 & -0.99 & 0.36 & \\
\hline USSR & 2900 & 1.23 & 3578 & -3.79 & -4.16 & 0.85 & \\
\hline Czechoslovakia & 2400 & 1.71 & 4110 & -5.56 & -6.28 & 1.18 & \\
\hline Switzerland & 26115 & 0.06 & 1580 & -0.12 & 1.04 & -0.15 & -0.30 \\
\hline Iceland & 21873 & 0.09 & 1955 & -0.22 & 0.91 & -0.22 & -0.44 \\
\hline Norway & 19963 & 0.10 & 2048 & -0.26 & 0.85 & -0.26 & -0.51 \\
\hline Denmark & 19830 & 0.16 & 3238 & -0.54 & 0.58 & -0.41 & -0.81 \\
\hline Sweden & 19257 & 0.09 & 1812 & -0.21 & 0.89 & -0.24 & -0.47 \\
\hline Germany & 16754 & 0.20 & 3427 & -0.69 & 0.40 & -0.51 & -1.02 \\
\hline Finland & 18070 & 0.16 & 2925 & -0.51 & 0.59 & -0.41 & -0.80 \\
\hline Luxembourg & 16331 & 0.36 & 5930 & -1.38 & -0.30 & -0.91 & -1.81 \\
\hline France & 15913 & 0.10 & 1636 & -0.22 & 0.85 & -0.26 & -0.51 \\
\hline Austria & 15441 & 0.11 & 1717 & -0.25 & 0.82 & -0.28 & -0.55 \\
\hline Netherlands & 14521 & 0.17 & 2428 & -0.57 & 0.57 & -0.42 & -0.83 \\
\hline Belgium & 14457 & 0.18 & 2637 & -0.55 & 0.50 & -0.46 & -0.91 \\
\hline Italy & 13176 & 0.13 & 1691 & -0.29 & 0.74 & -0.32 & -0.64 \\
\hline United Kingdom & 12024 & 0.23 & 2707 & -0.69 & 0.31 & -0.56 & -1.12 \\
\hline Ireland & 8353 & 0.25 & 2170 & -0.68 & 0.18 & -0.64 & -1.26 \\
\hline Spain & 7452 & 0.15 & 1123 & -0.18 & 0.64 & -0.38 & -0.75 \\
\hline Greece & 4619 & 0.31 & 1437 & -0.58 & -0.07 & -0.78 & -1.55 \\
\hline Portugal & 3612 & 0.21 & 758 & 0.09 & 0.38 & -0.53 & -1.04 \\
\hline Turkey & 1293 & 0.50 & 649 & 1.36 & -0.92 & -1.26 & -2.50 \\
\hline Japan & 19437 & 0.10 & 1942 & -0.25 & 0.87 & -0.25 & -0.50 \\
\hline United States & 18434 & 0.28 & 5112 & -1.01 & 0.08 & -0.70 & -1.38 \\
\hline Canada & 16056 & 0.26 & 4221 & -0.92 & 0.14 & -0.66 & -1.31 \\
\hline Australia & 11364 & 0.35 & 3932 & -1.16 & -0.23 & -0.87 & -1.72 \\
\hline New Zealand & 10749 & 0.16 & 1709 & -0.33 & 0.60 & -0.40 & -0.79 \\
\hline OECD & & 0.20 & 3015 & -0.62 & 0.43 & -0.50 & -0.99 \\
\hline Rest of world & & 0.55 & 639 & 0.80 & -1.47 & 0.43 & \\
\hline World as a whole & & 0.34 & 1112 & -0.24 & -0.24 & -0.24 & \\
\hline
\end{tabular}

Source: Larsen and Shah, 1994.

${ }^{a} 1987$ data. 
solving it (by maintaining ecosystems that help to reduce wastes). In any case, however, the underlying principle would remain the same: recognition that all persons have the same right to enjoy the common services of nature, without consideration of race, wealth, or any other variable that might come to mind. ${ }^{24}$ As already noted many times, the poor would probably sell their rights cheaply, but whether they sold them cheaply or dearly the calculations made regarding the benefits a scheme of this type would bring the underdeveloped countries leave little room for doubt: as may be seen from column A of table 2, which shows the gains each country would derive from participating in the agreement (measured by the increase in GDP in the year 2000), the poor countries would receive notable benefits. The bill would be paid by the developed countries, which would only be granted permits for $25 \%$ of their projected emissions, and by most of the middle-income countries and emerging economies.

ii) Allocation of rights as a function of the projected GDP of each country for the year 2000 with respect to world GDP $(0.23 \mathrm{~kg}$ per dollar). Under this system, most of the low- and middle-income countries and the emerging economies would lose (column B), so they would not be willing to participate in a joint emission reduction effort which would only favour the developed countries.

iii) Allocation of rights in such a way that they would cover the projected emissions of the underdeveloped countries for the year 2000. These countries would therefore have no objections, in principle. The rest of the emission rights, up to the proposed maximum permissible level, would be shared out among the OECD countries as a function of, for example, their past emission levels or any other criterion considered to be acceptable. The results for this system

\footnotetext{
${ }^{24}$ However, we should not forget the role of population policy: a scheme like that proposed would favour the adoption of policies to promote high birth rates, discriminating against those countries which are trying or have tried to contain their population growth, and this might be ethically unacceptable.
}

(column C) indicate that many underdeveloped countries would gain by participating in an agreement of this nature, for a very simple reason: the economic value of the permits they could sell if they did not use them would exceed the cost of adopting new and less polluting technologies.

iv) Unilateral reduction of emissions by the OECD countries. Under this system (column D) the developed countries would assume that the other countries were not going to take any measures at all and would unilaterally reduce their emissions accordingly: exactly the same as in the previous case. The difference would be that the emission permits market would be limited to the participating developed countries, which would prevent them from taking advantage of the efficiency gains offered by the fact that in the underdeveloped countries the cost of reducing emissions or not using the permits allocated to them would be lower. As a result, the price of the permits (per ton of emissions) would rise from the US\$ 58 calculated by Larsen and Shah (1994) to US\$ 181.

On the whole, if emission permits were allocated according to the first or third of the above options, this would be a much more promising scheme than the previous ones with regard to the dual aspect we have been analysing. With regard to the environmental problem, this approach tries to achieve some social objectives which would permit global sustainability, and it is also a system which is compatible with incentives for the adoption of cleaner technologies. As regards the problem of poverty, it has the great advantage that, as it is a question of global common resources, enjoyment of its benefits does not depend on the arbitrary manner in which nature distributed its "gifts", and this would seem more acceptable from the point of view of equity.

\footnotetext{
${ }^{25}$ As noted time and again, in order to avoid further aggravation of the problems of poverty it is essential that the compensation received in this respect should not end up in the hands of those who do not need it. In this respect, it has been recommended that this compensation should take the form of a reduction of the external debt burden, which would make it possible to considerably ease the adjustment programmes and the accompanying budgetary cuts that would otherwise be necessary (Rotillon and Tazdaït, 1996).
} 


\section{VII}

\section{Conclusions}

In this study, we have analysed the possibilities of relieving their poverty problems offered to underdeveloped countries and regions by exploitation of the comparative advantages deriving from their endowment of environmental and natural resources, within the framework of international trade and without giving rise to further degradation of the environment but, on the contrary, ensuring its sustainability.

Five possible schemes were studied in the light of their potential contribution to solving both the problems of poverty and those of deterioration of the environment:

i) Ecological dumping, based on the supposedly greater acceptance of pollution by the most underprivileged segments of the world's population. This was rejected from both standpoints: both as potentially harmful to the environment and as ethically unjustifiable. Its apparent rationality was based on two unacceptable premises: consideration of human life as just another merchandise, and incomplete calculation of its true social costs.

ii) Production of goods which make intensive use of renewable or non-renewable natural resources with a market value. In this respect, emphasis was placed on the limits established by the sustainability of such operations, in the first case, and intergenerational equity, in the second. Emphasis was also placed on the fact that, with regard to the solution of environmental problems, such efforts to derive income from natural resources only permit the preservation of those which offer financial yields higher than the market interest rate, since the decision-making process does not take account of the positive externalities generated by the resource.

iii) Financial exploitation of certain services provided by natural areas. These were viewed as suitable areas for a certain type of environmentally committed tourism, which would make it possible to derive economic benefits from the so-called "cathedrals of nature", provided they were suitably managed, and as sources of raw materials for research, especially in the pharmaceutical industry. The dual problem presented by these two examples is that, from the environmental point of view, they do not solve the problem of all those environmental assets which generate very considerable (and in some cases vital) positive externalities but do not have an economically appropriable value, while from the point of view of the poverty problem they only offer solutions to those countries which are fortunate enough to possess such assets.

iv) Calculation of the economic value generated by the environmental externalities of various assets and ecosystems, for subsequent payment of the corresponding amount to their managers. This is a much more powerful scheme for solving the environmental problem, since it places a value on all assets and all their environmental functions, regardless of whether, through their exclusibility, a price can be charged for their use. Unfortunately, this suffers from the same limitation as the previous scheme with regard to the problem of poverty.

v) Finally, the scheme which we consider to be most promising for solving the two problems addressed is the trading on the market of the right to use common environmental resources, especially the capacity of the atmosphere (and the biosphere in general) to absorb wastes. Supranational management of the question of emissions into the atmosphere, for example, would not only make it possible to solve a very serious environmental problem but would also, with the proposed scheme, provide the most under-privileged countries and regions with very substantial financial resources, independently of their good or bad luck in terms of natural gifts.

The foregoing analysis economically values the environmental functions of natural resources and ecosystems, putting a price on them so that they will be treated accordingly. This may be unacceptable to those who reject the idea of treating the environment as a form of merchandise because they feel that in their relations with the biosphere human beings should not reduce it to the level of a good (Anderson, 1993, chap. 9). While we feel a natural sympathy for this approach, however, it should be remembered that what we are seeking is that those who need to do so should earn revenue 
from the ecological functions of the various ecosystems in order to safeguard them more efficiently, with due compensation for those who have to forgo their commercial exploitation. In this respect, the decisions on their preservation are not left to the market and their enjoyment is obviously shared: both features that run counter to their supposed nature of commercial goods. Naturally, the least promising schemes in both fields are those which are already in operation. The last two schemes analysed, which not only require a supranational institutional framework but also call for sacrifices by the more highly developed countries, would raise much more problems. Even so, from the point of view of both efficiency and equity they represent a much more promising approach in both senses: development and sustainability.

(Original: Spanish)

\section{Bibliography}

Albers, J., A. C. Fisher and W. M. Hanemann (1996): Valuation and management of tropical forests: Implications of uncertainty and irreversibility, Environmental and Resource Economics, vol. 8, No. 1, Dordrecht, Netherlands, Kluwer Academic Publishers.

Anderson, E. (1993): Value in Ethics and Economics, Cambridge, Massachusetts, Harvard University Press.

Anderson, K. (1996): Environmental standards and international trade, Proceedings of the World Bank Annual Conference on Development Economics, Washington, D. C., World Bank.

Azqueta, D. (1992): Social project appraisal and environmental impact assessment, Development Policy Review, vol. 10, No. 3, London, Overseas Development Institute.

-(1994): Valoración económica de la calidad ambiental, Madrid, McGraw-Hill.

Azqueta, D. and L. Pérez (1996): Gestión de espacios naturales: la demanda de servicios recreativos, Madrid, McGraw-Hill.

Azqueta-Bernar, D. (1996): El conocimiento indígena, Ecología política, vol. 11, Madrid, FUHEM/ ICARIA.

Barbier, E. B. and B. A. Aylward (1996): Capturing the pharmaceutical value of biodiversity in a developing country, Environmental and Resource Economics, vol. 8, No. 2, Dordrecht, Netherlands, Kluwer Academic Publishers.

Barnes, J. I. (1996): Changes in the economic use value of elephants in Botswana: The effect of international trade prohibition, Ecological Economics, vol. 18, No. 3, Amsterdam, Netherlands, Elsevier Science B. V.

Berck, P. and M. Roberts (1996): Natural resource prices: Will they ever turn up?, Journal of Environmental Economics and Management, vol. 31, No. 1, New York, Academic Press.

Bohm, P. and B. Larsen (1994): Fairness in a tradeablepermit treaty for carbon emissions reductions in $\mathrm{Eu}-$ rope and the former Soviet Union, Environmental and Resource Economics, vol. 4, No. 3, Dordrecht, Netherlands, Kluwer Academic Publishers.

Burton, P.S. (1996): Land use externalities: Mechanism design for the allocation of environmental resources, Journal of Environmental Economics and Management, 30, pp. 174-185, New York, Academic Press.

Chichilnisky, G. (1994): North-South trade and global environment, The American Economic Review, vol. 84, No. 4, Washington, D. C., American Economic Association.

Constanza, R., R. D’Arge and R. de Groot (1997): The value of the world's ecosystem services and natural capital, Nature, vol. 387, Washington, D. C., Macmillan Publishers, 15 May.

Copeland, B. R. and M. S. Taylor (1995a): Trade and transboundary pollution, The American Economic Review, vol. 85, No. 4, Washington, D. C., American Economic Association.

- (1995b): Trade and the environment: A partial synthesis, American Journal of Agricultural Economics, vol. 77, No. 3, Ames, Iowa, American Agriculture Economics Association.

Dixon, J. A., L. F. Scura and T. van't Hof (1995): Ecology and microeconomics as joint products: The Bonaire Marine Park in the Caribbean, in C.A. Perrings and others, Biodiversity Conservation, Dordrecht, Netherlands, Kluwer Academic Publishers.

EC (European Comunity) (1995): ExternE: Externalities of energy, Directorate-General XII, Science Research and Development, Luxembourg.

Elliot, R. (1995): Environmental Ethics, Oxford, U. K., Oxford University Press.

Fearnside, P.M. (1997): Environmental services as a strategy for sustainable development in rural Amazonia, Ecological Economics, vol. 20, No. 1, Amsterdam, Netherlands, Elsevier Science B. V.

Gómez, C.M. (1994): Desarrollo sostenible y gestión eficiente de los recursos naturales, in D. Azqueta and A. Ferreiro (eds.), Análisis económico y gestión de recursos naturales, Madrid, Alianza Editorial. 
Goodland, R. and H. H. Daly (1992): Three steps towards global environmental sustainability, Development. Journal of the Society for International Development, No. 2, Oxford, U. K., Basil Blackwell.

(1996): If tropical log export bans are so perverse, why are there so many?, Ecological Economics, vol. 18, No. 3, Amsterdam, Netherlands, Elsevier Science B.V.

Goodstein, E. S. (1995): Economics and the Environment, Englewood Cliffs, New Jersey, Prentice Hall.

Gottfried, R. R., C. D. Brockett and W.C. Davis (1994): Models of sustainable development and forest resource management in Costa Rica, Ecological Economics, vol. 9, No. 2, Amsterdam, Netherlands, Elsevier Science B.V.

Grey, F. (1995): Assessing Economic Benefits of Protected Areas, Melbourne, Economist at Large and Associates for the UIMC.

Grossman, G. M. and A.B. Krueger (1995): Economic growth and the environment, Quarterly Journal of Economics, vol. CX, No. 2, Cambridge, Massachusetts, Harvard University.

Klaasen, G. A., F. R. Forsund and M. Amann (1994): Emission trading in Europe with an exchange, Environmental and Resource Economics, vol. 4, No. 4, Dordrecht, Netherlands, Kluwer Academic Publishers.

Krugman, P. R. and M. Obstfeld (1995): Economía internacional: teoría y política, Madrid, McGraw-Hill.

Larsen, B. and A. Shah (1994): Global tradeable carbon permits, participation incentives and transfers, $O x$ ford Economic Papers, vol. 46, special issue, London, Oxford University Press.

Lee, J.R. (1996): Basic attributes of trade and environment: What do the numbers tell us?, Ecological Economics, vol. 19, No. 33, Amsterdam, Netherlands, Elsevier Science B.V.

Lockwood, M. (1997): Integrated value theory for natural areas, Ecological Economics, vol. 20, No. 1, Amsterdam, Netherlands, Elsevier Science B.V.

López Ramón, F. (1996): Fuentes del régimen jurídico de los espacios naturales protegidos, in D. Azqueta and L. Pérez, Gestión de espacios naturales: la demanda de servicios recreativos, Madrid, McGraw-Hill.

Martínez-Alier, J. (1992): Obstáculos distributivos contra la política ambiental internacional, Información comercial española, No. 711, Madrid, Ministerio de Industria, Secretaría de Estado de Comercio, November.

Pearce, D. and J. Warford (1993): World without End, Oxford, U.K., Oxford University Press.

Rauscher, M. (1994): On ecological dumping, Oxford Economic Papers, vol. 46, special issue, London, Oxford University Press.
Reed, W. J. (1994): Una introducción a la economía de los recursos naturales y su modelización, in D. Azqueta and A. Ferreiro (eds.), Análisis económico y gestión de recursos naturales, Madrid, Alianza Editorial.

Ross, J. (1996): Treasure of the Costa Grande, Sierra Magazine, San Francisco, California, Sierra Club of San Francisco, August.

Rotillon, G. and T. Tazdaït (1996): International bargaining in the presence of global environmental change, Environmental and Resource Economics, vol. 8, No. 3, Dordrecht, Netherlands, Kluwer Academic Publishers.

Schaltegger, S. and T. Thomas (1996): Pollution Added Credit Trading (PACT): New dimensions in emission trading, Ecological Economics, vol. 19, No. 1, Amsterdam, Netherlands, Elsevier Science B. V.

Schulz, C. E. (1996): Trade policy and ecology, Environmental and Resource Economics, vol. 8, No. 1, Dordrecht, Netherlands, Kluwer Academic Publishers.

Sedjo, R. A., J. Wisniewski, A.V. Sample and J.D. Kinsman (1995): The economics of managing carbon via forestry: Assessment of existing studies, Environmental and Resource Economics, vol. 6, No. 2, Dordrecht, Netherlands, Kluwer Academic Publishers.

Shafik, N. (1994): Economic development and environmental quality: An econometric analysis, Oxford Economic Papers, vol. 46, special issue, London, Oxford University Press.

Shah, A. (1995): The Economics of Third World National Parks, Cheltenham, U. K., Edward Elgar.

Shyamsundar, P. and R. A. Kramer (1996): Tropical forest protection: An empirical analysis of the costs borne by local people, Journal of Environmental Economics and Management, vol. 31, No. 2, New York, Academic Press.

Simpson, R. D., R. A. Sedjo and J. W. Reid (1996): Valuing biodiversity for use in pharmaceutical research, Journal of Political Economy, vol. 104, No. 11, Chicago, Illinois, The University of Chicago Press.

Stähler, F. (1996): On international compensation for environmental stocks, Environmental and Resource Economics, vol. 8, No. 1, Dordrecht, Netherlands, Kluwer Academic Publishers.

Sterner, T. (1994): Discounting in a world of limited growth, Environmental and Resource Economics, vol. 4, No. 5, Dordrecht, Netherlands, Kluwer Academic Publishers.

Swanson, T. M. (1993): Regulating endangered species, Economic Policy, No. 16, London, Cambridge University Press, April.

(1994): The economics of extinction revisited and revised: A generalized framework for the analysis of the problems of endangered species and biodiversity 
losses, Oxford Economic Papers, vol. 46, special issue, London, Oxford University Press.

Van Kooten, G. C., S. C. Binkley and G. Delcourt (1995):

Effect of carbon taxes and subsidies on optimal forest rotation age and supply of carbon services, American Journal of Agricultural Economics, vol. 77, No. 2, Ames, Iowa, American Agriculture Economics Association.
Von Amsberg, J. (1993): Project Evaluation and the Depletion of Natural Capital: An Application of the Sustainability Principle, Environment working paper No. 56, Washington, D. C., World Bank, Environment Department.

Weitzman, M. L. (1994): On the "environmental" discount rate, Journal of Environmental Economics and Management, vol. 26, No. 2, New York, Academic Press. 